\title{
New Carabus Linnaeus, I 758 (Coleoptera Carabidae) from Caucasus and China. Description of the male of Carabus (Apo- tomopterus) ebian Cavazzuti et Rapuzzi, 2010
}

\author{
Ivan Rapuzzi
}

Via Cialla 47, 33040 Prepotto, Udine, Italy; email: info@ronchidicialla.it

\begin{abstract}
In this paper, five new subspecies of Carabus Linnaeus, 1758 (Coleoptera Carabidae) are described and figured. Three are from the south-eastern part of Sichuan province (China): Carabus (Apotomopterus) longeantennatus transjinshaensis n. ssp.; Carabus (Apotomopterus) benardi briseis n. ssp.; Carabus (Acoptopterus) vigilax rautenstrauchi n. ssp. The other two are from the Russian Caucasus (Ingushetia and Daghestan): Carabus (Tribax) kasakorum daghestanicola n. ssp.; Carabus (Tribax) kasakorum scintillans n. ssp. Furthermore, Carabus (Apotomopterus) ebian Cavazzuti et Rapuzzi, 2010 is considered a valid species after examination of a male specimen. The male aedeagus is described and figured for the first time.
\end{abstract}

KEY WORDS Apotomopterus; Acoptopterus; Tribax; Sichua; Caucasus; Russia; China.

Received 28.10.2018; accepted 13.11.2018; printed 30.12.2018; published online 07.01.2019

\section{INTRODUCTION}

After examination of several Carabus Linnaeus, 1758 specimens (Coleoptera Carabidae) from East Sichuan province in China and Central and East parts of the Russian Caucasus (Ingushezia and Daghestan), I have identified five new Carabus subspecies described in this paper. Furthermore, Carabus (Apotomopterus) ebian Cavazzuti et Rapuzzi, 2010 is considered a valid species after examination and description of a male specimen with the aedaegus.

\section{Carabus (Apotomopterus) longeantennatus transjinshaensis n. ssp. (Figs. 1-3)}

TYPE MATERIAL. Holotype male. China, Sichuan, Leibo, Shanlinggang env., VII.2018, Wang legit, Ivan Rapuzzi collection.
DESCRIPTION OF HOLOTYPE. Male. Length including mandibles $23.5 \mathrm{~mm}$, maximum width of elytra $7.4 \mathrm{~mm}$. Colour: upper and ventral side uniformly black; rather mat. Legs, palpi, antennae, and mandibles black. Head of normal shape; short neck; smooth head surface. Eyes big but moderately salient. Mandibles quite short. Palpi thin and very long, preapical segment of labial palpi bisetose. Antennae thin and very elongated protruding the apical third of elytra. Legs thin and very long. Pronotum small and narrow, nearly not transverse (1.08 times as broad as long); sides very moderately sinuate, nearly sub-parallel shape; upper surface faintly rugulose. Elytra very elongate and very narrow; convex; very narrow shoulders; quite rough sculpture, triploid slightly heterodyname type: primary chains larger and more relieved, interrupted by quite deep foveae; secondary and tertiary of the same size, uninterrupted; striae strongly punctured. 
Male aedeagus typical of the species: lateral view (Fig. 2), dorsal view (Fig. 3).

ETYMOLOGY. The given name wants to emphasise its type locality situated on the opposite side of the Jinsha Jiang River where the new subspecies was found.

Comparative notes. Carabus (Apotomopterus) longeantennatus Hauser, 1931 is a polytypical species largely widespread in Central China on the right side of the Jinsha Jiang and Chang Jiang rivers (Kleinfeld, 2011; Deuve, 2013). The new subspecies is closely related with $C$. (A.) longeantennatus yongshan Kleinfeld, 1999 inhabiting on the Wulian Mountains in the Northeast Yunnan on the other side of the Jinsha Jiang River valley. From $C$. $(A$.) longeantennatus yongshan it differs for the slender pronotum with sub parallel sides; more elongated elytra; rough and stronger elytral sculpture; apical portion of the median lobe of male aedeagus stronger curved with more acuminate apex.

\section{Carabus (Apotomopterus) benardi briseis n. ssp.} (Fig. 4)

TyPe Material. Holotype female. China, Sichuan, Leibo, Shanlinggang environs, VII.2018, Wang legit, Ivan Rapuzzi collection. Paratypes: two females, same data as holotype in Albert Rautenstrauch collections (Augsburg, Germany).

Description of holotype. Female. Length including mandibles $38 \mathrm{~mm}$, maximum width of elytra $13.3 \mathrm{~mm}$. Colour uniformly slate black, quite shiny. Legs, palpi, antennae, and mandibles black. Head of medium size; short neck; head surface punctured and strongly wrinkled, front smooth. Eyes big of hemispheric shape. Very long and thin palpi, penultimate segment of the labial palpi with three setae. Long antennae protruding to the half of the elytra. Pronotum large (1.3 times as broad as long), sides regularly rounded, sinuate just before the pronotal base; very few hind angles protruding behind the base; surface of pronotum strongly and uniformly rugulose. Elytra very elongate and extremely dilated before the base; preapical tooth of elytra very long and acuminate; shoulders narrow and rounded; slightly convex profile. Sculpture of elytra triploid heterodyname type; intervals very convexs; primary intervals forming short links interrupted by large foveae; secondary forming uninterrupted costae, slightly sinuated; tertiary of smaller size, less elevated and very often interrupted forming small grains.

VARIABILITY. Very small variability. The size of the two paratypes ranges from $36 \mathrm{~mm}$ to $37 \mathrm{~mm}$. In one paratype the elytral sculpture is characterized by less interrupted tertiary intervals.

Eтymology. The new subspecies is dedicated to Briseis or Hippodameia, a mythical queen at the time of the Trojan War, and wants to follow the tradition of using classics names for the taxa belonging to the Apotomopterus Hope, 1838 subgenus.

Comparative note. The new subspecies is close to $C$. (A.) benardi yiliangensis Deuve, 2002 but: longer and less sinuate pronotum with larger base, hind angles of pronotum less protruding behind base, elytra more elongate, elytral sculpture of heterodyname type.

\section{Carabus (Acoptopterus) vigilax rautenstrauchi n. ssp. (Figs. 5-7)}

TYPe MATERIAL. Holotype male. China, Sichuan, Leibo, Shanlinggang environs, VII.2018, Wang legit in collection Ivan Rapuzzi. Paratypes 4 females: same data as holotype, in Ivan Rapuzzi (1 female) and Albert Rautenstrauch collections (3 females) (Augsburg, Germany).

Description of holotype. Male. Length including mandibles $19.8 \mathrm{~mm}$, maximum width of elytra $7.1 \mathrm{~mm}$. Colour: upper and ventral sides of the body, legs, palpi, antennae, and mandibles uniformly black. Head quite thickened; disk faintly punctured, smoother front; supra antennary ridges very prominent. Big and prominent eyes. Palps very long and thin, apical segments of the labial and maxillar palps not dilated; penultimate segment of the labial palpi bi-setose. Antennae very long and thin, protruding behind the half of the elytra. Legs thin and extremely long. Small and slender pronotum (1.15 times as broad as long), sinuate; maximum width of pronotum at the apical third; sides fully margined and slightly bent upwards behind the pronotal base; hind angles of pronotum rounded and moderately protruding behind its base; surface of pronotum punctured and rough at the sides and behind the 


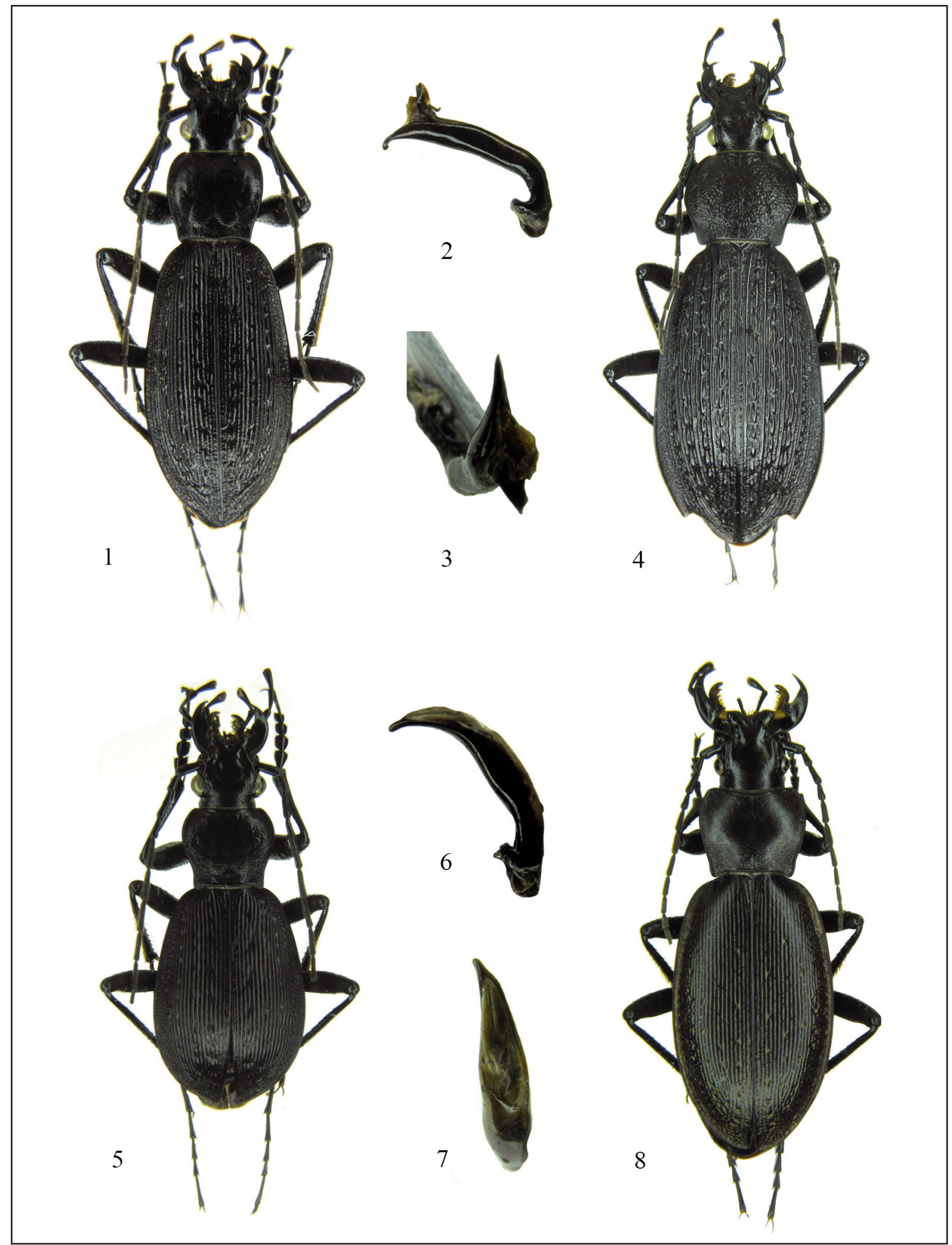

Figures 1-3. Carabus (Apotomopterus) longeantennatus transjinshaensis n. ssp. Fig. 1: holotype. Fig. 2: male aedeagus in lateral view. Fig. 3: male aedeagus in dorsal view. Figure 4. Carabus (Apotomopterus) benardi briseis n. ssp., holotype. Figures 5-7. Carabus (Acoptopterus) vigilax rautenstrauchi n. ssp. Fig. 5: holotype. Fig. 6: male aedeagus in lateral view. Fig. 6: male aedeagus in dorsal view. Figure 8. Carabus (Tribax) kasakorum daghestanicola n. ssp., holotype. 
base. Elytra oval, quite short and rounded; maximum width of elytra at the apical third; shoulders salient; sculpture triploid perfectly homodyname: primary interval forming chains of long segments interrupted by superficial foveae; secondary and tertiary interval of the same size forming uninterrupted lines; not punctured striae.

Male aedeagus is characteristic for the species but: in lateral view (Fig. 6), the apex of the median lobe is slender and more elongated. In dorsal view, the apex is very long and curved on le left (Fig. 7).

VARIABILITY. The variability concerns only the size that ranges from $21 \mathrm{~mm}$ to $22.1 \mathrm{~mm}$.

ETymology. The new subspecies is cordially dedicated to my friend and colleague Alber Rautestrauch (Augsburg, Germany).

Comparative notes. Close to $C$. (A.) vigilax vigilax Bates, 1890 but with more elongated head. Shape of elytra shorter and larger, rounded apex of elytra. Elytral sculpture of homodyname type, very regular and not rough up to the elytral apex; striae not punctate, primary foveae smaller and superficial. Apex of male aedeagus slender and more elongated.

\section{Carabus (Tribax) kasakorum daghestanicola n. ssp. (Fig. 8)}

TYPE MATERIAL. Holotype female: Russia, East Caucasus, Daghestan, Andiysky Mountain Range, Kharami pass, 2,500 m, 5.VII.2010, S. Rybalkin legit, Ivan Rapuzzi collection.

DesCriPTION OF HOLOTYPE. Female. Length including mandibles $25.3 \mathrm{~mm}$, maximum width of elytra $8.1 \mathrm{~mm}$. Colour: upper surface black with cupper lustre stronger on the elytral and prontal sides; primary fovea of elytra gold; rather shiny. Legs, palpi, antennae, and mandibles black. Thickened head, surface faintly punctured; front flat; short and large neck. Eyes quite big but not salient, quite flat. Mandible long and asymmetric: the left is slender and more developed than the right; the apical tooth of the left retinacle is very smooth, large and short; right retinacle bifid. Palpi thin but quite short, preapical segment of labial palpi bisetose. Antennae thin and quite short. Short legs. Pronotum sub-quadrate, quite transverse (1.25 times as broad as long), not sinuated sides; upper surface slightly flat and uniformly punctured; margined sides, slightly bent upwards behind the pronotal base; hind angles of pronotum rounded, protruding behind its base. Elytra elongate-oval shape; elytra slightly flat; elytral sculpture triploid homodyname type, very regular, convex intervals; primary chains sparsely interrupted by small but quite deep fovea; secondary and tertiary of the same size, uninterrupted; punctured striae.

ETymology. The new subspecies is named after the type locality.

COMPARATIVE NOTES. For its very smooth and regular elytral sculpture, the subquadrate pronotum is easily distinct from all the $C$. (T.) kasakorum Semenov, 1896 forms (kasakorum s. str., tschetschenicus Semenov, 1896 and scintillans n. ssp.). From C. (T.) georgiensis Gottwald, 1980, described as a valid species (Gottwald, 1980) and subsequently considered as a subspecies of $C$. (T.) kasakorum by Brezina (2003) or as a valid species (Deuve, 2004; Retezár, 2015), the new taxon is distinguish for the shape of pronotum (cordate in $C$. (T.) georgiensis) and the slender and elongated shape of elytra. It is morphologically similar to $C$. (T.) fausti Dohrn, 1873 inhabiting the same region, but easily distinguish by the very smooth and reduced apical tooth of the left retinacle (bifid in $C$. fausti), the smaller and flatted eyes (convex and larger in C. fausti), the subquadrate shape of pronotum (sinuate in $C$. fau$s t i$ ), the slender but less flat elytra (very flat and wider in C.fausti), the convex intervals of the eytral sculpture (flat and very smooth in C. fausti), the faint copper colour (black in $C$. fausti), the short legs and antennae (longer in C. fausti), and the black colour of tibiae and palpi (brown in C. fausti). For the significant and very specific morphological characters and for its geographical position very far to the East from C. kasakorum s.l., it very likely represents a different species. The examination of a male specimen will be necessary to clarify the status of this very interesting taxon.

\section{Carabus (Tribax) kasakorum scintillans n. ssp.} (Figs. 9-11)

TYPE MATERIAL. Holotype male: Russia, Caucasus, Ingushetia, South slopes of Skalistyi Mountain 
Range, Beyni village environs, 2,800 m, 21.V/19.VII.2018, Ivan Rapuzzi collection. Paratypes: 2 males and 3 females, same data as holotype, Ivan Rapuzzi collection.

DESCRIPTION OF HOLOTYPE. Male. Length including mandibles $22.5 \mathrm{~mm}$, maximum width of elytra $8 \mathrm{~mm}$. Colour: upper surface of elytra of intense copper-gold lustre, stronger on the sides and on the primary fovea; pronotum of the same colour of elytra but with darker disc; shiny. Legs, palpi, antennae, and mandibles black. Head slightly thickened; supra antennary ridges deep and wrinkled. Mandible long and strongly asymmetric: the left is slender and longer than the right; the apical tooth of the left retinacle is very smooth, large and short; right retinacle bifid, very long and thin palpi, preapical segment of the labial palpi with three setae. Antennae thin and long, reaching the half of the elytra. Legs long and quite slender. Transverse pronotum (1.49 times as broad as long), curved and not sinuated sides; very concave at the apex; upper surface wrinkled, strongly at the base; hind angles of pronotum rounded, bent downwards and protruding behind its base. Elytra of oval shape, quite short; very flat disc of elytra; large and salient shoulders; sculpture of elytra triploid type, slightly heterodyname; intervals strong and convex, rough at the apical third of elytra; primary chains of larger size, very often interrupted by large and quite deep fovea; secondary and tertiary of the same size, uninterrupted; punctured striae. Male aedeagus characteristic for the species but in general small and slender: in lateral view (Fig. 10) the apex of the median lobe is longer. In dorsal view the apex is strongly curved on le left (Fig. 11).

VARIABILITY. The variability of the paratypes concerns the size that is $21.5 \mathrm{~mm}$ for the paratype male and ranges from $23 \mathrm{~mm}$ to $25 \mathrm{~mm}$ for the paratypes females; the colour is copper-gold or copper-green, the females are in general darker and slightly mat.

ETYMOLOGY. The given name wants to point out the very shiny and bright colour unusual for the species.

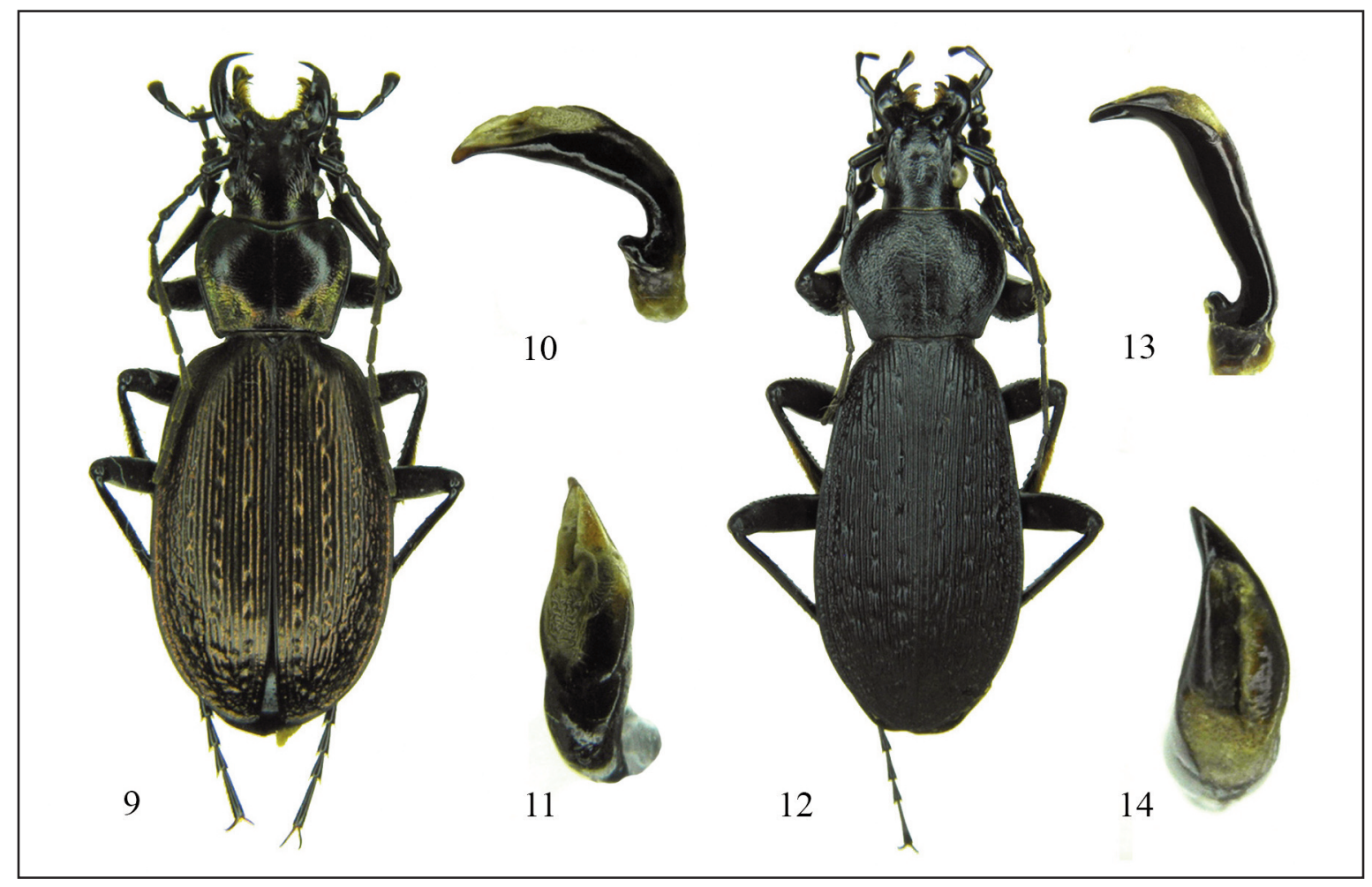

Figures 9-11. Carabus (Tribax) kasakorum scintillans n. ssp. Fig. 9: holotype. Fig. 10: male aedeagus in lateral view. Fig. 11: male aedeagus in dorsal view. Figures 12-14. Carabus (Apotomopterus) ebian Cavazzuti et Rapuzzi, 2010. Fig. 12: male. Fig. 13: male aedeagus in lateral view. Fig. 14: male aedeagus in dorsal view. 
Comparative nOte. Very well characterized subspecies. The closest form is $C$. kasakorum kasakorum but it is easily distinguished by the followings characters: shorter but less stout head; sides of pronotum not sinuate; shorter and wider elytra, very flat disc; shiny and brighter colour; male aedeagus shorter and slender, apex longer. From $C$. georgiensis Gottwald, 1980 the new taxon differs for: larger size; not sinuated pronotum; sculpture of elytra of heterodyname type, stronger and rough; shiny and bright colour; male aedeagus larger with less curved apex.

Carabus (Apotomopterus) ebian Cavazzuti et Rapuzzi, 2010 (Figs. 12-14)

Carabus (Apotomopterus) piriformis subsp. ebian Cavazzuti et Rapuzzi, 2010

Description of the Male of C. ebian Cavazzuti \& Rapuzzi, 2010. Length including mandibles 33 $\mathrm{mm}$, maximum width of elytra: $10 \mathrm{~mm}$. Colour uniformly black, shiny. Legs, palpi, antennae, and mandibles black. Head of normal size but elongate; quite long neck; head surface faintly punctured and superficially wrinkled. Pronotum very large, transverse (1.45 times as broad as long); maximum width of pronotum at the middle; sides rounded; hind angles very short and rounded; surface of pronotum uniformly punctured. Elytra very elongate and slender; shoulders narrow and rounded. Sculpture of elytra triploid slightly heterodyname type; convex intervals; primary intervals a little bit larger, forming short links interrupted by foveae; secondary and tertiary of the same size forming uninterrupted costae, very slightly sinuated.

Male aedeagus in lateral view (Fig. 13) very elongate; basal and median portion rectilinear of sub-conic shape; apical portion strongly curved; apex shorter and not dilated. In dorsal view (Fig. 14) quite curved on the left.

Comparative note. Cavazzuti \& Rapuzzi (2010) described, on the basis of two female specimens, this taxon as a subspecies of $C$. (A.) piriformis Deuve, 1997. Thanks to the kindness of Mr. Albert Rautenstrauch, I had the opportunity to study a male specimen of this taxon collected in its type locality. After its examination, I propose to consider C. (A.) ebian as a different species separate from $C$. piriformis and $C$. benardi as already hypothesized by the Authors in the discussion in the original description. Carabus (A.) ebian differs from C. benardi and $C$. piriformis for the following characteristics: longer neck; more transverse pronotum, not sinuated sides; surface of pronotum slightly rugulose; hind angles of pronotum shorter and larger; male aedeagus of sub-conic shape, apical lobe shorter of sub-cylindrical shape, not dilated, apex acuminate.

\section{ACKNOWLEDGEMENTS}

I want to thank my friends and colleagues Mr. Albert Rautenstrauch (Augsburg, Germany) for providing me part of the material fundamental for the study and Mr. Ief Peeters from Dilsen, Limburg (Belgium) for his help with literature.

\section{REFERENCES}

Brezina B., 2003. World Catalogue of the Genus Carabus L. Pensoft. Sofia-Moscow, 170 pp.

Cavazzuti P. \& Rapuzzi I., 2010. Nuovi taxa di Carabus L. delle provincie Cinesi di Yunnan, Sichuan e Gansu (Coleoptera, Carabidae). Lambillionea, 110: 154-168.

Deuve T., 2004. Illustrated Catalogue of the Genus Carabus of the World (Coleoptera: Carabidae). Pensoft, Sofia-Moscow, 461 pp.

Deuve T., 2013. Cychrus, Calosoma et Carabus de Chine. Pensoft, Sofia-Moscow, 286 pp., 137 fig.

Gottwald J., 1980. Revision der Untergattung Tribax der Gattung Carabus (Coleoptera, Carabidae). Acta Entomologica Bohemoslovaca, 77: 25-45.

Kleinfel F., 2011. Apotomopterus. Monographische Übersicht über das Subgenus Apotomopterus Hope, 1838 des Genus Carabus Linnaeus, 1758. Fürth: Frank Kleinfeld Publ., 107 pp., 174 fig.

Retezár I., 2015. Atlas of the Carabus of the Caucasus (Coleoptera, Carabidae). Mondat Kft., 134 pp., 79 figs., 238 plates. 